Agr. Biol. Chem., 40 (11), $2177 \sim 2180,1976$

\title{
Biosynthetic Pathway of Leaf Aldehyde in Farfugium japonicum Kitamura Leaves
}

\author{
Akikazu Hatanaka, Tadahiko Kajiwara, Jiro Sekiya and Haruatsu Hirata \\ Department of Agricultural Chemistry, Faculty of Agriculture, \\ Yamaguchi University, Yamaguchi 753 \\ Received May 24, 1976
}

\begin{abstract}
$3 Z$-Hexenal, 2E-hexenal (leaf aldehyde) and 1-undecene were first found in Farfugium japonicum Kitamura (japanese silver) leaves. On blending the leaves in the presence of oxygen, $2 E$-hexenal was enzymatically generated via a similar biosynthetic pathway to that in Thea sinensis leaves: via $3 Z$-hexenal from linolenic acid. However, unlike Thea sinensis leaves neither $3 Z$-hexenol (leaf alcohol) nor $2 E$-hexenol was found in $F$. japonicum leaves.
\end{abstract}

From early times, the leaves of Farfugium japonicum Kitamura (japanese silver) have been used as a home remedy for suppurating erup-

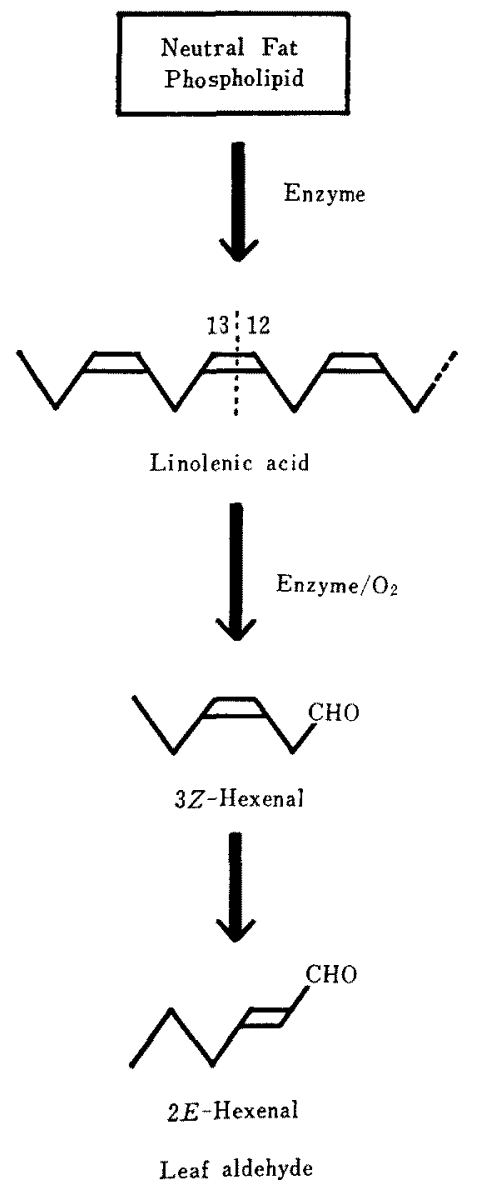

Scheme 1. Biosynthetic Pathway of Leaf Aldehyde in Farfugium japonicum Kitamura Leaves. tions. Leaf aldehyde, $2 E$-hexenal, was found as a biologically active substance in the leaves, ${ }^{1)}$ but the biosynthesis was not explored.

We found that $2 E$ - and $3 Z$-hexenal and the corresponding alcohols were formed from linolenic acid as shown in Scheme 1, when tea leaves were blended or mechanically ruptured in the presence of oxygen. ${ }^{2 \sim 12\}}$

To demonstrate whether or not $2 E$-unsaturated aldehydes are generally biosynthesized via $3 Z$-aldehydes from linolenic acid in fresh leaves, $F$. japonicum leaves were used.

\section{RESULTS AND DISCUSSION}

Identification of volatile components in Farfugium japonicum Kitamura leaves

Fresh $F$. japonicum leaves were blended with distilled water and the homogenates were steam-distilled. The distillate was extracted with ether and the crude essential oil was obtained from the ether extracts. Samples of the oils were quantitatively analyzed by GLC analyses. As 3Z-unsaturated aldehyde is easily isomerized to $2 E$-isomer in the homogenates of leaves, this aldehyde was followed by headspace vapour analysis according to the methods previously described. ${ }^{21} 3 Z$-Hexenal, $2 E$-hexenal, $n$-hexanal and 1 -undecene were first confirmed as the characteristic flavour components of the leaves by IR and MS spectral comparisons of the authentic specimens synthe- 
sized by unequivocal routes. ${ }^{5)}$ It is notable that the occurrence of $3 Z$-hexenol and $2 E$ hexenol was not confirmed in $F$. japonicum leaves unlike Thea sinensis leaves. ${ }^{2}$

Effect of blending, heating and oxygen on the formation of aldehydes

During blending in the presence of oxygen, there was rapid formation of aldehydes, e.g. $2 E$-hexenal and $n$-hexanal (Table I). As

Table I. Effect of Blending, Heating AND OXYGEN ON THE FORMATION OF ALDEHYDES

\begin{tabular}{|c|c|c|c|}
\hline Condition & $n$-Hexanal & 2E-Hexenal & 1-Undecene \\
\hline Non blended ${ }^{a}$ & trace & trace & trace \\
\hline \multicolumn{4}{|l|}{ Blended $\left.{ }^{b}\right)$} \\
\hline under air & $7.2^{d)}(100)^{e)}$ & $46.1(100)$ & $56.4(100)$ \\
\hline under $\mathrm{N}_{2}$ & $2.1 \quad(29)$ & $86.9(188)$ & $75.0(133)$ \\
\hline under $\mathrm{O}_{2}$ & $13.3(184)$ & $187.1(331)$ & $136.7(276)$ \\
\hline \multicolumn{2}{|c|}{ after heating ${ }^{e)} \quad-$} & $3.8(0.6)$ & $12.9(28)$ \\
\hline \multicolumn{4}{|c|}{ a) Steam-distilled without blending. } \\
\hline \multicolumn{4}{|c|}{ b) For $3 \mathrm{~min}$ at room temperature. } \\
\hline \multicolumn{4}{|c|}{ c) For $3 \mathrm{~min}$ at $100^{\circ} \mathrm{C}$. } \\
\hline \multicolumn{4}{|c|}{ d) $\mathrm{mg} / \mathrm{kg}$ of fresh leaves. } \\
\hline \multicolumn{4}{|c|}{ e) () : percentage $(\%)$} \\
\hline
\end{tabular}

shown in Table $I$, the formation of aldehydes was prevented by blending under an atmosphere of nitrogen and/or by heating intact leaves before blending. Based on results obtained, it is concluded that the volatile aldehydes, $n$-hexanal and $2 E$-hexenal, are generated enzymatically, when fresh $F$. japonicum leaf is blended under aerobic conditions.

Conversion of fatty acids to aldehydes during blending

The fatty acids constituting the lipids in intact and blended $F$. japonicum leaves, respectively, were quantitatively analyzed by GLC analyses. The major fatty acids of the lipids in the fresh leaves were linolenic, linoleic and palmitic acid, and these fatty acids were not found in free fatty acid fraction. During blending under aerobic conditions, the amounts of linolenic and linoleic acid in both the neutral fat and phospholipid fractions decreased markedly, but the decreases were not ac-
TABle II. Contents of Fatty AcIDS IN Farfugium japonicum KITAMURA

\begin{tabular}{lcccc}
\hline \multirow{2}{*}{ Fraction } & \multicolumn{2}{c}{ Linolenic acid } & \multicolumn{2}{c}{ Linoleic acid } \\
\cline { 2 - 5 } & $0 \min ^{a)}$ & $3 \min ^{b)}$ & $0 \min ^{a)}$ & $3 \min ^{b)}$ \\
\hline Free fatty acid & trace & trace & trace & trace \\
Neutral fat & $74.3^{\circ)}$ & 67.9 & 82.5 & 58.5 \\
Phospholipid & 67.5 & 41.3 & 87.0 & 42.8 \\
\hline Total lipid & 141.8 & 109.2 & 169.5 & 101.3 \\
\hline a) & Blending at zero time: inactivated at & $65^{\circ} \mathrm{C}$ for \\
& 12 min and then blended for 3 min at room \\
temperature. \\
b) Blended for 3 min at room temperature. \\
o) mg/kg of fresh leaves sampled on the 3rd of July, \\
1976.
\end{tabular}

companied by increases in free fatty acids as shown in Table II, and the formation of $2 E$ hexenal and $n$-hexanal respectively was observed (Table I).

Formation of aldehydes from linolenic and linoleic acid

The correlation between increase in $2 E$ hexenal and $n$-hexanal, and decrease in linolenic and linoleic acid, clearly indicates that the fatty acids constituting the lipids of $F$. japonicum leaves were converted to the volatile aldehydes during blending under aerobic conditions. On blending the leaves with added linolenic or linoleic acid, $2 E$-hexenal or $n$-hexanal increased remarkably (Table III). The results clearly indicate that during blending in the presence of oxygen, linolenic acid liberated from neutral lipid and phospholipid is stereospecifically split into $2 E$-hexenal via $3 Z$-hexenal in $F$. japonicum leaves as well as Thea sinensis leaves. The details of the $3 Z$ hexenal-forming enzyme will be reported. ${ }^{13}$

Table III. Formation of Aldehydes from UNSATURATED FatTy ACIDS

\begin{tabular}{lrr}
\hline Fatty acid added $^{a>}$ & \multicolumn{1}{c}{$n$-Hexanal } & $2 E$-Hexenal $\left.\right|^{b)}$ \\
\hline Control & $26.1^{c\rangle}(100)$ & $83.5(100)$ \\
Linolenic acid & $254.8 \quad(997)$ & $82.3(101)$ \\
Linoleic acid & $31.5(121)$ & $183.8(225)$ \\
\hline
\end{tabular}

a) Blended with each fatty acid $\left(1.8 \times 10^{-8} \mathrm{M}\right)$ for $3 \mathrm{~min}$ at room temperature and then steamdistilled.

b) $3 Z$-Hexenal was isomerized to $2 E$-isomer during steam-distillation.

o) $\mathrm{mg} / \mathrm{kg}$ fresh leaves. 
On the other hand, neither $3 Z$-hexenol nor $2 E$-hexenol was found in $F$. japonicum unlike Thea sinensis leaves. ${ }^{2)}$ The alcohol dehydrogenase activity was not detected according to the method in tea $\mathrm{ADH}{ }^{4}$ ) Thus, it seems that the redox systems involving alcohol dehydrogenase which convert $3 Z$-hexenal and $2 E$ hexenal to the corresponding alcohols do not occur in $F$. japonicum leaves.

\section{EXPERIMENTAL}

IR spectra were taken on a Hitachi EPI-G2. MS spectra were recorded on a Japan Spectroscopic Model TAM-01SG spectrometer. Gas chromatography was performed using a Shimadzu GC-4B equipped with FID. GLC analyses of the essential oil were carried out on a $3 \mathrm{~m} \times 3 \mathrm{~mm}$ stainless steel column packed with $20 \%$ PEG- $20 \mathrm{M}$ on celite $545,60 \sim 80$ mesh. Analyses of fatty acids were performed on a $1 \mathrm{~m} \times 3 \mathrm{~mm}$ stainless steel column packed with $20 \%$ PEG-adipate on Chromosorb W, $60 \sim 80$ mesh.

\section{Materials}

Fresh leaves of Farfugium japonicum Kitamura were used. Linoleic and linolenic acid ( $99 \%$ purity) were purchased from Wako Pure Chemical Co., Osaka, Japan. Other chemicals were synthesized through unequivocal routes and were proved to be of $99 \%$ purity. ${ }^{7,9)}$

\section{Preparation of essential oil}

After $F$. japonicum leaves $(40 \mathrm{~g})$ were blended with distilled water $(200 \mathrm{ml})$ in a Waring blender for $3 \mathrm{~min}$ at room temperature, the mixture was steam-distilled to give $500 \mathrm{ml}$ of distillate. The distillate was saturated with $\mathrm{NaCl}$ and extracted three times with $50 \mathrm{ml}$ of ether. The combined ether solutions were dried over anhydrous $\mathrm{Na}_{2} \mathrm{SO}_{4}$. Evaporation of solvent gave the crude essential oil.

\section{Preparation of fatty acids}

A crude lipid fraction was prepared from fresh $F$. japonicum leaves $(100 \mathrm{~g})$ by blending and subsequent extraction with $\mathrm{CHCl}_{3}-\mathrm{MeOH}$ mixture $(2: 1, \mathrm{v} / \mathrm{v}$, 1 liter). The crude lipid thus obtained was separated into acetone-soluble and acetone-insoluble fractions. The acetone-soluble fraction was evaporated and the residue dissolved in ether-petrol $(1: 1)$. The free fatty acids in the organic solution were extracted with $1 \%$ sodium carbonate and the lower was acidified with $\mathrm{HCl}$. The mixture was extracted with ether and free fatty acids were obtained after evaporation of ether. The fraction not extracted with sodium car- bonate was saponified with alcoholic potassium hydroxide, unsaponified material being extracted with ether and discarded. The solution of potassium salts was acidified with $\mathrm{HCl}$ and fatty acids derived from the neutral fat fraction were extracted with ether. The phospholipid fraction was repeatedly extracted from the acetone-insoluble fraction with $\mathrm{CHCl}_{3}-\mathrm{MeOH}(1: 1)$ and the concentrate of combined extracts was hydrolyzed with $20 \% \mathrm{HCl}(160 \mathrm{ml})$ in boiling water for $14 \mathrm{hr}$ under $\mathbf{N}_{2}$. The fatty acids liberated from the phospholipid fraction were extracted with ether. Fatty acids from each fraction were esterified with $\mathrm{CH}_{2} \mathrm{~N}_{2}$ and aliquots were analyzed by GLC.

\section{Isolation and identification of 1-undecene and 3Z- hexenal}

1-Undecene: the essential oil prepared as described above was fractionated to give 1 -undecene by preparative GLC: column; $20 \%$ PEG-20M ( $3 \mathrm{~m} \times 5 \mathrm{~mm})$, column temp.; $170^{\circ} \mathrm{C}$. The IR and MS spectra of the natural compound were identical with those authentic specimens; IR $\nu_{\max }^{\mathrm{fl1m}} \mathrm{cm}^{-1} ; 1825\left(\mathrm{CH}_{2}=\mathrm{CH}-\right), 1640$ $\left(\mathrm{CH}_{2}=\mathrm{CH}-\right), 995\left(\mathrm{CH}_{2}=\mathrm{CH}-\right), 915\left(\mathrm{CH}_{2}=\mathrm{CH}-\right), \mathrm{MS}$ $(\mathrm{m} / \mathrm{e}) ; \quad 42(19.8 \%), \quad 56(78.2 \%), \quad 70(100.0 \%), \quad 83$ $(80.2 \%), 97(57.4 \%), 111(26.7 \%), 126(18.8 \%), 157$ $(19.8 \%)$

$3 Z$-Hexenal: as $3 Z$-hexenal was easily isomerized in the homogenates of leaves, the blended leaves were extracted immediately with ether. The aldehyde fraction including 1-undecene was prepared by preparative GLC and then the 2, 4-dinitrophenylhydrazone derivative was obtained according to the method reported previously. ${ }^{63}$ The purified derivative of natural aldehyde was identified with that of $3 Z$-hexenal obtained by synthesis, mp $100 \sim 102^{\circ} \mathrm{C}$ (from ethanol); IR $\nu_{\max }^{\mathrm{KB}}: 3300(-\mathrm{NH}-), 1620(-\mathrm{C}=\mathrm{N}-), 730(\mathrm{Z},-\mathrm{CH}=$ $\mathrm{CH}-$ ).

\section{Effect of blending, heating and oxygen on the formation} of volatile components

Effect of blending: volatile components of intact $F$. japonicum leaves (non-blended sample) were prepared without blending, and other volatile samples were prepared after blending for $3 \mathrm{~min}$ at room temperature.

Effect of heating: fresh $F$. japonicum leaves were immersed in a water bath kept at $100^{\circ} \mathrm{C}$ for $3 \mathrm{~min}$ and then blended.

Effect of oxygen: fresh $F$. japonicum leaves were blended in nitrogen, oxygen or air for $3 \mathrm{~min}$ at room temperature. The essential oil from each sample was prepared by the method described above and analyzed by GLC under the above conditions.

\section{Conversion of fatty acid to aldehydes during blending}

For blending time 0 , fatty acids were prepared from $F$. japonicum leaves inactivated at $65^{\circ} \mathrm{C}$ for $12 \mathrm{~min}$. 
Other fatty acids were prepared after blending fresh leaves with distilled water for $3 \mathrm{~min}$ according to the preparation method described above. Fatty acids in each fraction were quantitatively analyzed by GLC under the above conditions.

\section{REFERENCES}

1) T. Kosuge and M. Yokota, Yakugaku Zasshi, 82, 422 (1963).

2) A. Hatanaka and T. Harada, Phytochem., 12, 2341 (1973).

3) A. Hatanaka, T. Kajiwara and S. Tomohiro, Agr. Biol. Chem., 38, 1819 (1974).

4) A. Hatanaka, T. Kajiwara, S. Tomohiro and H. Yamashita, ibid., 38, 1835 (1974).

5) T. Kajiwara, T. Harada and A. Hatanaka, ibid.,
39, 243 (1975).

6) J. Sekiya, W. Kawasaki, T. Kajiwara and A. Hatanaka, Agr. Biol. Chem., 39, 1677 (1975).

7) T. Kajiwara, Y. Odake and A. Hatanaka, ibid., 39, 1617 (1975).

8) H. Aoshima, T. Kajiwara, A. Hatanaka, H. Nakatani and K. Hiromi, ibid., 39, 2255 (1975).

9) A. Hatanaka, T. Kajiwara and T. Harada, Phytochem., 14, 2589 (1975).

10) J. Sekiya, S. Numa, T. Kajiwara and A. Hatanaka, Agr. Biol. Chem., 40, 185 (1976).

11) A. Hatanaka, J. Sekiya and T. Kajiwara, Phytochem., 15, 487 (1976).

12) A. Hatanaka, T. Kajiwara and J. Sekiya, ibid, 15, 1125 (1976).

13) A. Hatanaka, J. Sekiya and T. Kajiwara, Plant Cell Physiol., 181, in press (1977). 